\title{
Snacking, sugar-sweetened beverage consumption and child obesity in low-income households
}

\author{
Christine E. Walsh, Rebecca Seguin-Fowler, Alice Ammerman, \\ Karla Hanson, Stephanie B. Pitts Jilcott, Jane Kolodinsky, \\ Marilyn Sitaker and Susan Ennett \\ (Author affiliations can be found at the end of the article)
}

Received 19 February 2020 Revised 20 April 2020 Accepted 20 April 2020

\begin{abstract}
Purpose - Snacking contributes to one-quarter of children's total daily energy intake in the USA, with many snack foods being nutrient-poor and energy-dense. Snacking and sugary beverage consumption have been identified as potential contributors to childhood overweight and obesity and may play a particularly important role among children from socioeconomically disadvantaged households that generally display higher rates of obesity. This exploratory study investigated associations between consumption of snack foods, sugar-sweetened beverages (SSB) and overweight and obesity in children from low-income households.

Design/methodology/approach - Data from households that participated in a multi-state cost-offset (CO-CSA) community supported agriculture intervention in 2016 and $2017(n=305)$ were analyzed. Fixed effect regression models were used to estimate associations between child monthly consumption of salty snack foods; sweet snack foods and SSBs; and child weight status, accounting for demographic characteristics.

Findings - No associations were found between snack or SSB consumption and child overweight. However, household income was significantly, negatively related to all three consumption variables (Salty snacks: $\beta=$ $-0.09, \mathrm{SE}=0.04, p=0.02 ;$ Sweet snacks: $\beta=-0.10, \mathrm{SE}=0.04, p=0.01 ; \mathrm{SSB}: \beta=-0.21, \mathrm{SE}=0.05, p=0.0001$ ). The results suggest that household income may play an important role in children's snacking and SSB behaviors among more disadvantaged households.

Practical implications - Factors beyond snack food and SSB consumption should be explored to better understand childhood overweight and obesity, and to inform future obesity interventions.

Originality/value - Socioeconomic disparities in childhood obesity are an ongoing policy-relevant issue within the USA and internationally. This study provides new information about child snacking behaviors in a unique, low-income population and contributes to the evidence base regarding the role household context in shaping child consumption behaviors.
\end{abstract}

Keywords Dietary intake, Children, Drinks, Overweight, Disadvantaged groups, Processed foods

Paper type Research paper

This material is based upon work that is supported by the National Institute of Food and Agriculture, US Department of Agriculture, under award number 2014-08347. The author is grateful to Drs Alice Ammerman, Karla Hanson and Rebecca Seguin who contributed to the initial study design, content knowledge and review of the manuscript. Additionally, Drs Jane Kolodinsky, Stephanie B. Jilcott Pitts and Marilyn Sitaker reviewed the manuscript and provided extremely valuable expertise and input. The author also thanks Dr Susan Ennett, for support throughout the writing process and the decision to submit the manuscript for publication. All authors reviewed and had final approval of the paper. The author is also grateful to the study participants and communities, without whom this study would not have been possible. 


\section{Introduction}

Childhood overweight and obesity in the USA present a pressing and persistent public health concern. Obesity contributes to poor health outcomes during childhood and predicts increased morbidity across the lifetime, including greater risk of depression, cancer and cardiovascular and metabolic diseases (Halfon et al., 2013). Reports over the past several years suggest that childhood obesity rates in the USA have stabilized or decreased in recent years (Ogden et al., 2015; Ogden et al., 2016). However, the most current US estimates indicate that prevalence of childhood overweight and obesity remains high (Skinner et al., 2018). In fact, rates of childhood overweight and obesity have reached a zenith, with $35.1 \%$ of children and adolescents ages 2-19 years considered overweight or obese, defined as body mass index (BMI) $\geq 85$ th percentile (Skinner et al., 2018). At the same time, this increase is not distributed evenly across groups and socioeconomic disparities in childhood obesity are substantial. Previous studies have demonstrated that child obesity is linked to socioeconomic status (SES) and children from low-income households have elevated risk of obesity in comparison to children with higher family incomes when accounting for race and ethnicity (Ogden et al., 2016; Jin and Jones-Smith, 2015; Frederick et al., 2014).

The ongoing childhood obesity epidemic may in part be related to shifting population trends in snacking behaviors. Evidence points to an increase over the past five decades in youth consumption of "empty" calories in the form of processed snack foods and sugarsweetened beverages (SSBs), and this increase has paralleled rates of childhood obesity. In one study, Poti et al. (2014) found that from 1977 to 2006, the per cent of daily calories attributed to snacking increased from 21 to $27 \%$ in all children ages 2-18 years. Apart from a general increase in snacking during childhood, consumption of calorie dense foods and SSBs is substantially higher among children who are minorities and low income (Miles and SiegaRiz, 2017). SES may play a role in children's snack food consumption as low SES can be a barrier to accessing healthy, affordable foods (Larson et al., 2009) and early psychosocial stress has been linked to overeating in children who are low-income (Miller et al., 2018).

In light of evidence indicating alarming rates of childhood obesity and widening disparities, there is a pressing need to identify dietary factors that contribute to obesity among children, especially those at higher risk. Snacking has been identified by some as a major contributor to the childhood obesity epidemic due to the concurrent rise in children's consumption of processed snack foods and child obesity (Piernas and Popkin, 2010). Yet, few studies have explicitly examined a link between snacking behavior and obesity, specifically among children from low-income backgrounds. Although research has shown that younger children with overweight and obesity tend to have higher energy intakes than children without obesity (Branum et al., 2011), it has not yet been shown that greater energy intake in the form of snacks is linked to child obesity. Additionally, since SES impacts diet in various ways, such as physical and financial access to more healthful foods (Carroll-Scott et al., 2013), it is of interest to explore characteristics specific to a low-income population that may be related to snacking behavior.

Thus, this study aimed to examine the relationship between child consumption of processed snack foods and SSBs, and child BMI and overweight in children from lowincome households. Specifically, we asked: is higher child snack consumption associated with higher BMI and overweight? We hypothesized that higher child snack food and SSB consumption would be related to higher child BMI and overweight/obesity status. A further objective of this analysis was to describe patterns and correlates of child snack food and SSB consumption among a population of low-income households participating in a costoffset (CO), community-supported agriculture (CSA) program. 


\section{Methods}

Cross-sectional data for this analysis were taken from the baseline survey of a longitudinal, multi-state randomized controlled trial of the Farm Fresh Foods for Healthy Kids (F3HK) intervention, a CO-CSA program coupled with tailored nutrition education for low-income families with children (Seguin et al., 2017). The intervention included participation in a 1524 week summer CO-CSA share (50\% subsidized), weekly payments allowing Supplemental Nutrition Assistance Program (SNAP) electronic benefits transfer, nine skill-based healthy eating classes, and the provision of basic kitchen tools.

Individuals from 12 communities with existing CSAs in four states (Oregon, New York, North Carolina, and Vermont) were recruited for the study. Participants were recruited inperson at local social service agencies, community sites (e.g. schools, libraries, churches), and through marketing materials. Eligible households were enrolled into the program during spring 2016 and 2017. Following enrollment and baseline assessment, participants were randomly assigned to either intervention (immediate CO-CSA) or control (delayed intervention) using a computer-generated randomizer to ensure equivalent group sizes at each CSA program site. The baseline survey was administered in March 2016 to June 2016 and February 2017 to June 2017 among two separate cohorts enrolling in the F3HK. The study protocol was reviewed and approved by the Institutional Review Boards at the University of Vermont (protocol ID \#16-393) and Cornell University (protocol ID \#1501005266). Further information on participant recruitment and preliminary results of the CO-CSA trial is presented elsewhere (Seguin et al., 2017).

\section{Participants}

Data came from 305 low-income households with at least one child aged 2-12 years. Of the total 685 households initially screened during recruitment, $542(79 \%)$ were eligible for study inclusion. Respondent eligibility included being 18 years of age or older; an English-speaker; the primary caregiver of a child 2-12 years old; a monthly household income at or below $185 \%$ the federal poverty level (FPL); willingness to use SNAP benefits or own money to purchase the $50 \%$ CO-CSA share; and having an active email address and access to a computer or tablet. The final number of eligible households who agreed to participate in the study was 305 in New York $(n=93)$, North Carolina $(n=77)$, VT $(n=71)$ and Washington $(n=64)$.

\section{Variables and data sources}

Dietary data were obtained for one focal child aged 2-12 years in each household. The vast majority of dietary information was reported by the caregiver who prepared most of the child's meals $(95.2 \%)$.

Child dietary consumption. Three dietary frequency variables were examined: total monthly consumption of SSBs, total monthly consumption of sweet snack foods and total monthly consumption of salty snack foods. Consumption of SSBs and processed snack foods at baseline was collected for both caregiver and child via an online questionnaire based on the second version of the beverage and snack questionnaire (BSQ2) (Neuhouser et al., 2009). The BSQ2 includes questions regarding frequency of consumption of beverages, savory snacks and sweets in the last week. Seven frequency response options were provided, ranging from "never or $\leq$ once/week" to " $4 \geq$ times/day" and converted into times per month. Child dietary consumption variables were transformed by natural log to better normalize their distribution and account for outliers in the data. 
Salty snacks: Foods included were low fat or non-fat potato chips, tortilla chips and corn chips; regular chips; or other salty snacks (e.g. Cheese nibs, Chex mix, gold fish crackers and pretzels).

Sweet snacks: Defined as candy (e.g. chocolate, candy bars, jelly bellies, gummies and Lifesavers); doughnuts, pop tarts or other breakfast pastries; cookies, brownies, pies and cakes; low or nonfat frozen desserts (e.g. ice cream, frozen yogurt, popsicles, sherbet, milkshakes); and regular ice cream and milkshakes.

SSBs: These included regular or $2 \%$ flavored milk, nonfat or $1 \%$ flavored milk; fruit drinks; sport drinks; regular sodas; energy drinks; and coffee or tea drinks containing added sugar.

Caregiver and child demographics. Caregiver and child demographic characteristics were collected as part of the baseline survey, including questions for caregiver race/ethnicity, education and household income. Caregivers provided the age and gender of the focal child. Information on child race/ethnicity was not included as part of baseline data collection.

Household food insecurity. Household food security was measured using the six-item short form module of the USDA Food Security Survey Module with a 30-day reference period (Bickel et al., 2000). Items ask respondents about the conditions and experiences of food insufficiency due to resource limitations. Participants were considered to live in a food insecure household if they met criteria for two or more items.

Household fruit and vegetable access. Accessibility of fruits and vegetables (FV) in the home was assessed by caregivers from a four-item scale. These questions ask "How often are the following true? In my home, there is fruit available to have as a snack, In my home, there is a vegetable available to have as a snack, In my home, there are cut-up vegetables in the fridge for my child to eat and In my home, there is fresh fruit on the counter, table, or somewhere else where my child can easily get to it" (Robinson-O'Brien et al., 2009). Four ordinal response options were available (hardly ever, rarely, sometimes, often) and numerically coded as 1-4.

Child body mass index and obesity status. Trained research staff collected data on child body weight and height. Measures were taken without shoes and in lightweight clothing according to standard procedures (Lohman et al., 1988). These anthropometric measures were used to calculate child BMI percentiles according to growth charts (U.S. Department of Health and Human Services (USDHHS), 2018) and to identify child overweight and obesity status. Children with a BMI $\geq 85^{\text {th }}$ percentile for age were categorized as overweight or obese.

\section{Statistical analysis}

Descriptive analyses of sample characteristics were stratified by child weight status. We conducted chi-square significance tests for categorical variables and two-tailed independent t-tests for means of continuous variables (i.e. child age). Outliers for total intake frequency were identified following best practices (Aguinis et al., 2013) and extreme cases were dropped $(n=5)$. The final analytic sample size was 300 . We conducted a $t$-test sample size calculation test for multiple linear regression using the $G^{*}$ Power software package (Faul et al., 2009). The test revealed a sample size of 152 is necessary to correctly identify an effect, assuming a small effect size $\left(f^{2}=0.05\right)$ based on previous research (Nisak et al., 2018), with 80 power and 5\% significance level. Given the sample size of 300 households, our analysis was found to be adequately powered.

Mean frequency of consumption for salty snacks, sweet snacks and SSBs was examined by child weight status also using two-tailed independent t-tests. Multiple logistic regression was performed to examine the relationship of the three dietary predictor variables on child weight status. Analyses controlled for child age, child sex, race, caregiver education, 
household income, FV access and food insecurity. Prior studies have shown these variables as significantly associated with child BMI and overweight (Larson et al., 2009; Gable and Lutz, 2000; Bowman, 2007; Wang and Beydoun, 2007). Second, generalized linear regression models were used to separately analyze the relationship between demographic characteristics and both snack types, and SSB consumption frequency.

To account for the clustered sample across four geographically diverse states, we used a fixed-effects model to estimate regression analyses. With the fixed-effects model, any factors that might be associated with state cluster that are not observed and explicitly controlled are held constant (Branum et al., 2011). All analyses were performed using SAS version 9.4 (SAS Institute, Inc., Cary, NC) with a significance level of $p<0.05$.

\section{Results}

Sample characteristics

Baseline characteristics for focal children in low-income households enrolled in the F3HK trial are shown in Table 1. The average age of children in the total sample was 6.1 years. Children who were overweight and obese were slightly but significantly older compared with children who were not overweight or obese ( 6.7 years vs 5.7 years, $p=0.004$ ). More than half of the total sample were female, while significantly more male children were classified as overweight/obese $(\phi=0.01)$. The majority of the sample was White $(77 \%)$. Though a greater share of Black children were overweight or obese $(17.2 \%)$ compared to those not overweight $(10.8 \%)$, this difference was not significant $(p=0.21)$.

Approximately half of adult caregivers reported attaining a college degree. Caregivers of children who were not overweight were significantly more likely to have a college degree or more compared with caregivers of children who were overweight/obese $(\phi=0.006)$. The majority of households at baseline reported low or very low food security. Most households reported having access to acceptable quality FV sometimes or often. Approximately $20 \%$ of children lived in households with low FV access (i.e. hardly ever or rarely had access to fresh FV). More than half of households had an annual income less than $\$ 25,000$, and nearly three quarters of households had annual incomes less than $\$ 35,000$. The proportion of households with incomes less than $\$ 35,000$ a year was significantly higher for households with children who are overweight and obese compared with households with children neither overweight nor obese $(\phi=0.02)$.

\section{Child snack and sugar-sweetened beverages consumption}

Analytic results indicated that average monthly snack food consumption and SSB consumption was frequent among children in this sample. As shown in Table 2, average monthly consumption for children in this sample was 23.3 times for salty snacks, 34.1 times for sweets and 41.8 times for SSBs. The range for salty snack frequency was 0 to 137 times per month and 0 to a maximum of 249 sweet snacks consumed per month, while consumption of SSBs ranged from 0 to 270 times per month. There was a significant difference in the mean monthly salty snack frequency for children by weight status $(\phi=0.02)$, such that overweight or obese children ate salty snacks more frequently than their non-overweight counterparts. Similarly, monthly SSB frequency was significantly higher among overweight/obese children compared with their non-overweight/obese counterparts $(p=0.04)$. We did not find a significant difference between the log of monthly sweet snack frequency for overweight children and children not overweight $(p=0.60)$.

Results of logistic regression analysis are depicted in Table 3, which contains the associations between snack and SSB frequency measures and child overweight. Nonsignificant variables for household income, FV access and food insecurity were omitted to 
Child overweight status

\begin{tabular}{|c|c|c|c|c|c|}
\hline & $\begin{array}{c}\text { Total } \\
N=300\end{array}$ & $\begin{array}{l}\text { Overweight/ } \\
\text { Obese } n=122\end{array}$ & $\begin{array}{l}\text { Not overweight } \\
\mathrm{n}=174\end{array}$ & Test statistic & $p$-value \\
\hline Child Age, Mean (SD) & $6.12(3.0)$ & $6.7(3.0)$ & $5.7(2.9)$ & -3.04 & $0.003^{*}$ \\
\hline $\begin{array}{l}\text { Child sex, }(\%) \\
\text { Male } \\
\text { Female } \\
\text { Race, } \%\end{array}$ & $\begin{array}{l}47.2 \\
52.8\end{array}$ & $\begin{array}{l}55.6 \\
44.4\end{array}$ & $\begin{array}{l}41.2 \\
58.8\end{array}$ & 6.07 & $0.01 *$ \\
\hline $\begin{array}{l}\text { White } \\
\text { Black } \\
\text { Multiracial } \\
\text { Other }\end{array}$ & $\begin{array}{r}76.6 \\
13.6 \\
5.3 \\
5.0\end{array}$ & $\begin{array}{r}71.3 \\
17.2 \\
7.4 \\
4.1\end{array}$ & $\begin{array}{r}79.6 \\
10.8 \\
4.0 \\
5.1\end{array}$ & 5.22 & 0.16 \\
\hline $\begin{array}{l}\text { Caregiver education, }(\%) \\
\text { High School or less } \\
\text { Some college/technical school } \\
\text { College graduate } \\
\text { Graduate or professional degree }\end{array}$ & $\begin{array}{l}19.7 \\
31.5 \\
38.4 \\
10.5\end{array}$ & $\begin{array}{r}29.0 \\
29.3 \\
31.5 \\
9.7\end{array}$ & $\begin{array}{l}13.0 \\
32.3 \\
43.5 \\
10.2\end{array}$ & 12.62 & $0.006^{*}$ \\
\hline $\begin{array}{l}\text { Household income, }(\%) \\
\text { Less than } \$ 9,999 \\
\$ 10,000-\$ 14,999 \\
\$ 15,000-\$ 19,999 \\
\$ 20,000-\$ 24,999 \\
\$ 25,000-\$ 34,999 \\
\$ 35,000-\$ 49,999 \\
\$ 49,999-\$ 74,999\end{array}$ & $\begin{array}{r}18.4 \\
10.0 \\
10.0 \\
14.4 \\
20.4 \\
20.1 \\
6.7\end{array}$ & $\begin{array}{r}20.3 \\
13.0 \\
14.6 \\
13.8 \\
16.3 \\
16.3 \\
5.7\end{array}$ & $\begin{array}{r}17.0 \\
8.0 \\
6.8 \\
14.8 \\
23.3 \\
22.7 \\
7.4\end{array}$ & 2.36 & $0.02 *$ \\
\hline $\begin{array}{l}\text { Household Food Security, }(\%) \\
\text { Food Secure } \\
\text { Food Insecure }\end{array}$ & $\begin{array}{l}43.5 \\
56.5\end{array}$ & $\begin{array}{l}40.3 \\
59.7\end{array}$ & $\begin{array}{l}45.8 \\
54.2\end{array}$ & 1.07 & 0.30 \\
\hline $\begin{array}{l}\text { Household FV Access, }(\%) \\
\text { Hardly ever } \\
\text { Rarely } \\
\text { Sometimes } \\
\text { Often }\end{array}$ & $\begin{array}{r}3.3 \\
18.2 \\
61.4 \\
17.2\end{array}$ & $\begin{array}{r}5.7 \\
15.4 \\
61.0 \\
17.9\end{array}$ & $\begin{array}{r}1.7 \\
19.9 \\
61.9 \\
16.5\end{array}$ & 2.39 & 0.13 \\
\hline
\end{tabular}

Notes: Test statistic reflects t-statistic (two-tailed t-test) for differences in group means and f-statistic $\left(\chi^{2}\right.$ test) for differences in proportions by child overweight/obesity status. Overweight or obese children significantly differ from those not overweight in the sample by age, sex, caregiver education and household income. *Italic text denotes statistically significant at $p<0.05$

improve model fit. Data revealed that neither snacking or SSB frequency variables were significantly related to child weight status. However, child age was significantly and positively associated with child overweight, such that for each additional year in age, the log odds of being overweight increased by 0.11 ( $\mathrm{SE}=0.04, p=0.01$ ). Additionally, compared with girls, boys displayed a 0.67 increase in the log odds of being overweight $(\mathrm{SE}=0.25, p=$ 0.01 ) holding all other variables constant.

When examining predictors of snacking and SSB consumption frequency, results in Table 4 demonstrated that several demographic variables were significantly related to the child frequency consumption measures. In particular, household income was significantly, negatively related to all three dietary behaviors, indicating that greater household income is 
associated with lower frequency of salty snacks, sweet snacks and SSBs among the children in this sample, controlling for all other variables. For total sweet snack frequency, there was an additional negative association with household FV access, suggesting that a one-unit increase in access to fruits and vegetables is significantly related to a 0.76 factor decrease in frequency of consuming sweet snacks per month, holding all else constant $(\phi=0.009)$. Household food access was also negatively associated with child monthly SSB consumption $(B=-0.48, p=0.003)$. Unlike the two snacking measures, older child age was significantly related to greater monthly SSB consumption $(B=0.09, p=0.004)$, as well as household food insecurity such that being in a food insecure household is associated with a 1.73 factor increase in monthly SSB consumption in this sample of children. Child sex, caregiver race and caregiver education were not associated with any of the child dietary frequency measures.

\section{Discussion}

The rise in childhood obesity rates has coincided with increases in the consumption of energy-dense, processed snack foods and SSBs during childhood (Piernas and Popkin, 2010),

\begin{tabular}{llccr}
\hline & \multirow{2}{*}{ Total } & \multicolumn{2}{c}{ Overweight status } & \\
& $N=300$ & Overweight/Obese & Not overweight & Difference \\
\hline $\begin{array}{l}\text { Salty Snacks, } \\
\text { Mean (SD) }\end{array}$ & $\begin{array}{l}23.3(20.6) \\
0-137\end{array}$ & $26.3(23.1)$ & $20.8(1.4)$ & $5.5^{*}$ \\
$\begin{array}{l}\text { Range } \\
\text { Sweet Snacks, }\end{array}$ & $34.1(35.4)$ & & & \\
Mean (SD) & $0-249$ & $34.5(28.5)$ & $32.4(36.5)$ & 2.1 \\
Range & $41.8(54.2)$ & & & \\
SSB, & $0-270$ & $48.9(54.0)$ & $35.6(53.7)$ & $13.3^{*}$ \\
Mean (SD) & & & & \\
Range & & & &
\end{tabular}

Notes: Abbreviations: SSB, sugar-sweetened beverage; SD, standard deviation. Comparison of average snack or SSB consumption frequency by child overweight/obesity status. On average, children who are overweight or obese consume 5.5 more salty snacks and 13.3 more SSBs per month than their nonoverweight counterparts. Italic text denotes statistically significant difference. $* P<0.05$, two-tailed t-test

\begin{tabular}{lcccccc}
\hline Predictor & $\beta$ & $S E$ & Wald $\chi^{2}$ & $P$ & OR & $95 \%$ CI $(L L, U L)$ \\
\hline Salty snacks & 0.19 & 0.13 & 2.16 & 0.14 & 1.21 & $(0.94,1.56)$ \\
Sweet snacks & 0.01 & 0.13 & 0.01 & 0.94 & 1.01 & $(0.78,1.31)$ \\
SSB & 0.12 & 0.08 & 1.93 & 0.17 & 1.12 & $(0.95,1.32)$ \\
Child age & 0.11 & 0.04 & 6.51 & $0.01^{*}$ & 1.12 & $(1.03,1.22)$ \\
Child sex (ref = male) & -0.64 & 0.25 & 6.54 & $0.01^{*}$ & 0.53 & $(0.32,0.86)$
\end{tabular}

Notes: Abbreviations: SSB, sugar-sweetened beverage; SE, standard error; OR, Odds Ratio; CI, Confidence Interval. Associations between log of total monthly snack and SSB consumption variables and child overweight status. Logistic regression coefficients are displayed with standard errors. Non-significant control variables were omitted, which included caregiver race, education, household income, household fruit and vegetable access and household food insecurity. Italic text denotes statistically significant predictor of child overweight status (Wald $\chi^{2}$ test). $* p<0.05$

Table 2.

Average monthly snack food and sugar-sweetened beverage consumption, for overall sample and by child overweight status
Table 3. Multiple logistic regression analysis of children's total monthly snack and SSB consumption frequency on overweight status $(n=300)$ 


\section{Table 4.}

Multivariate generalized linear model estimates for demographic factors on monthly snacking and SSB

consumption frequency

\begin{tabular}{lcccccl} 
& \multicolumn{2}{c}{ Salty snacks } & \multicolumn{2}{c}{ Sweet snacks } & \multicolumn{2}{c}{ SSB } \\
& $\beta(\mathrm{SE})$ & $P$ & $\beta(\mathrm{SE})$ & $P$ & $\beta(\mathrm{SE})$ & \multicolumn{1}{c}{$P$} \\
\hline Child age & $0.01(0.02)$ & 0.65 & $0.03(0.02)$ & 0.10 & $0.09(0.03)$ & $0.004^{* *}$ \\
Child sex (ref = Male) & $-0.03(0.13)$ & 0.82 & $0.16(0.12)$ & 0.19 & $-0.15(0.18)$ & 0.43 \\
Race (ref = White) & & & & & & \\
Black & $-0.16(0.22)$ & 0.49 & $-0.23(0.29)$ & 0.76 & $-0.04(0.32)$ & 0.90 \\
Multiracial & $0.03(0.29)$ & 0.93 & $-0.12(0.22)$ & 0.42 & $0.63(0.41)$ & 0.13 \\
Other & $-0.39(0.29)$ & 0.18 & $0.09(0.28)$ & 0.59 & $-0.41(0.42)$ & 0.34 \\
Caregiver Education (ref = Graduate Degree) & & & & & \\
HS or less & $-0.004(0.26)$ & 0.99 & $-0.32(0.26)$ & 0.21 & $0.18(0.38)$ & 0.64 \\
Some college & $-0.14(0.23)$ & 0.55 & $-0.21(0.22)$ & 0.35 & $0.22(0.33)$ & 0.51 \\
College degree & $-0.05(0.22)$ & 0.81 & $-0.21(0.21)$ & 0.32 & $0.05(0.32)$ & 0.86 \\
HH Income & $-0.09(0.04)$ & $0.02^{*}$ & $-0.10(0.04)$ & $0.01^{*}$ & $-0.21(0.05)$ & $0.0001^{* * *}$ \\
HH FV access & $-0.06(0.11)$ & 0.60 & $-0.28(0.11)$ & $0.009^{* *}$ & $-0.48(0.16)$ & $0.003^{* *}$ \\
HH Food Insecurity (ref = Food & $0.09(0.14)$ & 0.50 & $0.07(0.14)$ & 0.63 & $0.55(0.20)$ & $0.007^{* *}$ \\
secure) & & & & & &
\end{tabular}

Notes: Abbreviations: SSB, sugar-sweetened beverage; SE, Standard Error; HH, household; HS, high school; FV, fruit and vegetable. Associations between demographic characteristics and child dietary behaviors. Italic text denotes statistically significant fixed effect regression estimates and standard errors. $* P<0.05 ; * * P<0.01 ; * * * P<0.001$

sparking public efforts targeting these dietary behaviors to improve childhood weight status and related health outcomes (Gortmaker et al., 2011). However, there remains an existing gap in the literature concerning an explicit link between child snack intake and weight status among children who are low income. In the current analysis, we strived to address this gap by investigating the relationship between snacking and BMI in children participating in the F3HK intervention trial; specifically, we examined child consumption of three separate snack/beverage types: salty snacks, sweet snacks and SSBs.

In contrast to our initial hypothesis, we found that none of the dietary consumption measures were significantly related to child weight status, after controlling for demographic and household factors. This finding is not entirely surprising as other studies have similarly found a lack of association between snacking and BMI (Field et al., 2004). A longitudinal study following adolescent girls over 10 years showed that consuming snack foods - including chips, baked goods and candy - did not predict BMI (Phillips et al., 2004). When examining SSB consumption, Johnson et al. (2007) similarly found no evidence that SSB intake at 5 or 7 years of age predicted weight status at age 9 years. The data presented here further add to the literature supporting that snacking does not appear to be an independent factor related to childhood overweight and obesity in children from low-income households.

Additionally, the exploratory nature of this analysis shed light on the snacking and SSB consumption patterns in this sample of low-income children. The findings indicate an alarmingly high rate of monthly snack food and SSB consumption among this sample of children ages 2-12 years, with children consuming an average of nearly one salty snack a day, and over one sweet snack and SSB a day. These results are consistent with recent studies showing that $63 \%$ of children in the USA consumed on average at least one SSB daily and 30\% consumed two or more a day (Rosinger et al., 2017). Investigations beyond the USA similarly report high adolescent consumption of refined sugars in the form of 
snacks and SSBs (Sholeye et al., 2018), and suggest a global pattern of increased snacking that is particularly salient in younger populations.

When examining potential child, caregiver and household characteristics related to snacking and SSB consumption, our results revealed that household income was associated with all three of the child consumption variables, while household fruit and vegetable access and child age were significantly related to only child's total monthly sweet snack and SSB consumption. Household food insecurity was additionally associated with total monthly SSB consumption. These findings are consistent with current empirical research. It is wellknown that household context shapes dietary behaviors, and those in lower SES households are more likely to develop high-risk cardiovascular behaviors (Lee and Cubbin, 2002). Our results found that household access to fruits and vegetables and income category was significantly inversely related to sweet snack and SSB consumption frequency among children. Household food insecurity was additionally significantly inversely associated to SSB consumption.

The findings around household income are intriguing given that the high number of households near or below the FPL due to the low-income requirement for participation in the F3HK trial. Extant literature has previously shown that SSB consumption is disproportionately higher among low-income children. A study using nationally representative data found that low-income children had 1.29 times the odds of regular soda consumption compared with high-income children (Han and Powell, 2013). Our results similarly show that lower income appears be implicated in child intake frequency of SSB and both snack types, even after accounting for other factors such as caregiver education. This suggests that income remains a determinant of dietary behavior in children among an already low-income sample. Recent literature suggests that resource constraints can influence household food purchasing, particularly as processed snack foods and beverages tend to be inexpensive and may be more readily available in lowincome food environments (Mielmann and Brunner, 2019). Consumption of high sugar, sodium and fat foods has also been theorized as a coping strategy for perceived stress (Lazarus and Folkman, 1984; Lehman and Rodin, 1989). In turn, greater financial-related stress may encourage purchasing decisions that prioritize taste and immediate satisfaction of food products over nutritional quality and longer-term health consequences (Papoutsi et al., 2019).

Further research is needed to unravel underlying mechanisms and interactions connected to how low SES contributes to snacking patterns, such as material resources, neighborhood food environment and caregiver and child stress. Finally, though the present study did not show snacking or SSB consumption as related to overweight in young children ages 2-12 years, the dietary habits formed during this early period of development may have longer term consequences beyond the scope of this analysis. Longitudinal research should be conducted to better clarify the role of childhood snacking on later health outcomes.

\section{Limitations}

This study is not without limitations. The cross-sectional nature of the data makes causal inference impossible. Due to the reliance on a non-probability design, the findings regarding children's snacking behaviors may have limited generalizability, though we argue that the focus on low-income households adds important information about a particularly vulnerable population. Additionally, selection bias is a concern as more highly educated participants voluntarily enrolled in the CO-CSA intervention, potentially indicating greater motivation to or already engage in 
healthier dietary behaviors. These distinct caregiver features may in turn influence their children's snacking consumption such that the sample might not accurately represent other children with low-income backgrounds in the USA. The data represented here may also be prone to recall and social desirability bias, as is often the case with dietary measures and when conducting surveys with children (Livingstone et al., 2004). However, the use of a validated dietary questionnaire with a comprehensive list of products and descriptions should have helped minimize miscategorization and better capture all snacks and SSBs consumed. Finally, this analysis not include other key behavioral and physiological variables associated with child overweight, such as physical activity or metabolic processes. Future analyses should continue to examine the role of snack food consumption in children's overall diet and health while considering these other factors.

Limitations notwithstanding, this study provides new information about child snacking behaviors in a low-income population, and contributes to the evidence base regarding the role of household context in shaping child SSB intake. Despite evidence suggesting that consumption of snack foods does not appear to be independently related to child overweight, public health interventions and policies should not necessarily discontinue efforts to target these dietary behaviors. Processed food snacking and SSB consumption contributes a substantial portion to children's diets, which can influence future dietary patterns and longer-term health outcomes. These results demonstrate that factors beyond snack food and SSB consumption should be explored to better understand child overweight and obesity.

\section{References}

Aguinis, H., Gottfredson, R.K. and Joo, H. (2013), "Best-practice recommendations for defining, identifying, and handling outliers", Organizational Research Methods, Vol. 16 No. 2, pp. 270-301.

Bickel, G., Nord, M., Price, C., Hamilton, W. and Cook, J. (2000), Guide to Measuring Household Food Security, Department of Agriculture Food and Nutrition Service, Alexandria.

Bowman, S. (2007), "Low economic status is associated with suboptimal intakes of nutritious foods by adults in the national health and nutrition examination survey 1999-2002", Nutrition Research, Vol. 27 No. 9, pp. 515-523.

Branum, A.M., Parker, J.D., Keim, S.A. and Schempf, A.H. (2011), "Prepregnancy body mass index and gestational weight gain in relation to child body mass index among siblings", American Journal of Epidemiology, Vol. 174 No. 10, pp. 1159-1165.

Carroll-Scott, A., Gilstad-Hayden, K., Rosenthal, L., Peters, S.M., McCaslin, C., Joyce, R. and Ickovics, J. R. (2013), "Disentangling neighborhood contextual associations with child body mass index, diet, and physical activity: the role of built, socioeconomic, and social environments", Social Science and Medicine, Vol. 95, pp. 106-114.

Faul, F., Erdfelder, E., Buchner, A. and Lang, A.G. (2009), "Statistical power analyses using G* power 3.1: tests for correlation and regression analyses", Behavior Research Methods, Vol. 41 No. 4, pp. 1149-1160.

Field, A.E., Austin, S.B., Gillman, M.W., Rosner, B., Rockett, H.R. and Colditz, G.A. (2004), "Snack food intake does not predict weight change among children and adolescents", International Journal of Obesity, Vol. 28 No. 10, pp. 1210-1216.

Frederick, C.B., Snellman, K. and Putnam, R.D. (2014), "Increasing socioeconomic disparities in adolescent obesity", Proceedings of the National Academy of Sciences, Vol. 111 No. 4, pp. 1338-1342. 
Gable, S. and Lutz, S. (2000), "Household, parent, and child contributions to childhood obesity", Family Relations, Vol. 49 No. 3, pp. 293-300.

Gortmaker, S.L., Swinburn, B.A., Levy, D., Carter, R., Mabry, P.L., Finegood, D.T., Huang, T., Marsh, T. and Moodie, M.L. (2011), "Changing the future of obesity: science, policy, and action", The Lancet, Vol. 378 No. 9793, pp. 838-847.

Halfon, N., Larson, K. and Slusser, W. (2013), "Associations between obesity and comorbid mental health, developmental, and physical health conditions in a nationally representative sample of US children aged 10 to 17", Academic Pediatrics, Vol. 13 No. 1, pp. 6-13.

Han, E. and Powell, L.M. (2013), "Consumption patterns of sugar-sweetened beverages in the United States", Journal of the Academy of Nutrition and Dietetics, Vol. 113 No. 1, pp. 43-53.

Jin, Y. and Jones-Smith, J.C. (2015), "Associations between family income and children's physical fitness and obesity in California, 2010-2012", Preventing Chronic Disease, Vol. 12.

Johnson, L., Mander, A.P., Jones, L.R., Emmett, P.M. and Jebb, S.A. (2007), "Is sugar-sweetened beverage consumption associated with increased fatness in children?", Nutrition, Vol. 23 Nos 7/8, pp. 557-563.

Larson, N.I., Story, M.T. and Nelson, M.C. (2009), "Neighborhood environments: disparities in access to healthy foods in the US", American Journal of Preventive Medicine, Vol. 36 No. 1, pp. 74-81.

Lazarus, R.S. and Folkman, S. (1984), Stress, Appraisal, and Coping, Springer Publishing Company, New York, NY, pp. 150-153.

Lee, R.E. and Cubbin, C. (2002), "Neighborhood context and youth cardiovascular health behaviors", American Journal of Public Health, Vol. 92 No. 3, pp. 428-436.

Lehman, A.K. and Rodin, J. (1989), "Styles of self-nurturance and disordered eating", Journal of Consulting and Clinical Psychology, Vol. 57 No. 1, pp. 117-122.

Livingstone, M.B.E., Robson, P.J. and Wallace, J.M.W. (2004), "Issues in dietary intake assessment of children and adolescents”, British Journal of Nutrition, Vol. 92 No. S2, pp. S213-S222.

Lohman, T.G., Roche, A.F. and Martorell, R. (1988), "Anthropometric standardization reference manual”, Champaign: Human Kinetics Books, Vol. 177, pp. 3-8.

Mielmann, A. and Brunner, T.A. (2019), "Consumers' snack choices: current factors contributing to obesity", British Food Journal, Vol. 121 No. 2.

Miles, G. and Siega-Riz, A.M. (2017), "Trends in food and beverage consumption among infants and toddlers: 2005-2012", Pediatrics, Vol. 139 No. 6, p. e20163290.

Miller, A.L., Gearhardt, A.N., Retzloff, L., Sturza, J., Kaciroti, N. and Lumeng, J.C. (2018), "Early childhood stress and child age predict longitudinal increases in obesogenic eating among lowincome children", Academic Pediatrics, Vol. 18 No. 6, pp. 685-691.

Neuhouser, M.L., Lilley, S., Lund, A. and Johnson, D.B. (2009), "Development and validation of a beverage and snack questionnaire for use in evaluation of school nutrition policies", Journal of the American Dietetic Association, Vol. 109 No. 9, pp. 1587-1592.

Nisak, A., Rachmah, Q., Mahmudiono, T. and Segalita, C. (2018), "Snacking energy-dense food related to childhood obesity", Journal of Nutrition and Food Sciences, Vol. 8 No. 5, pp. 1-5.

Ogden, C.L. Carroll, M.D. Fryar, C.D. and Flegal, K.M. (2015), "Prevalence of obesity among adults and youth: United States, 2011-2014".

Ogden, C.L., Carroll, M.D., Lawman, H.G., Fryar, C.D., Kruszon-Moran, D., Kit, B.K. and Flegal, K.M. (2016), "Trends in obesity prevalence among children and adolescents in the United States, 19881994 through 2013-2014", JAMA, Vol. 315 No. 21, pp. 2292-2299.

Papoutsi, G., Klonaris, S. and Drichoutis, A. (2019), "The health-taste trade-off in consumer decision making: an experimental approach", British Food Journal. 
Phillips, S.M., Bandini, L.G., Naumova, E.N., Cyr, H., Colclough, S., Dietz, W.H. and Must, A. (2004), "Energy-dense snack food intake in adolescence: longitudinal relationship to weight and fatness", Obesity Research, Vol. 12 No. 3, pp. 461-472.

Piernas, C. and Popkin, B.M. (2010), "Trends in snacking among US children”, Health Affairs, Vol. 29 No. 3, pp. 398-404.

Poti, J.M., Slining, M.M. and Popkin, B.M. (2014), "Where are kids getting their empty calories? Stores, schools, and fast-food restaurants each played an important role in empty calorie intake among US children during 2009-2010", Journal of the Academy of Nutrition and Dietetics, Vol. 114 No. 6 , pp. 908-917.

Robinson-O’Brien, R., Neumark-Sztainer, D., Hannan, P.J., Burgess-Champoux, T. and Haines, J. (2009), "Fruits and vegetables at home: child and parent perceptions", Journal of Nutrition Education and Behavior, Vol. 41 No. 5, pp. 360-364.

Rosinger, A. Herrick, K. Gahche, J. and Park, S. (2017), "Sugar-sweetened beverage consumption among U.S. youth, 2011-2014", NCHS Data Brief. No 271, National Center for Health Statistics, Hyattsville, MD.

Seguin, R.A., Morgan, E.H., Hanson, K.L., Ammerman, A.S., Pitts, S.B.J., Kolodinsky, J., Sitaker, M., Becot, F.A., Connor, L.M., Garner, J.A. and McGuirt, J.T. (2017), "Farm fresh foods for healthy kids (F3HK): an innovative community supported agriculture intervention to prevent childhood obesity in low-income families and strengthen local agricultural economies", BMC Public Health, Vol. 17 No. 1, p. 306.

Sholeye, O., Animasahun, V., Salako, A. and Oduwole, A. (2018), "Snacking and sweetened beverage consumption among adolescents in Sagamu, Southwest Nigeria", Nutrition and Food Science, Vol. 48 No. 3, pp. 442-452.

Skinner, A.C., Ravanbakht, S.N., Skelton, J.A., Perrin, E.M. and Armstrong, S.C. (2018), "Prevalence of obesity and severe obesity in US children, 1999-2016”, Pediatrics, Vol. 141 No. 3, p. e20173459.

U.S. Department of Health and Human Services (USDHHS) (2018), "A SAS program for the 2000 CDC growth charts (ages 0 to $<20$ years)", available at: www.cdc.gov/nccdphp/dnpao/growthcharts/ resources/sas.htm (accessed 12 October 2019).

Wang, Y. and Beydoun, M.A. (2007), "The obesity epidemic in the United States - gender, age, socioeconomic, racial/ethnic, and geographic characteristics: a systematic review and Metaregression analysis", Epidemiologic Reviews, Vol. 29 No. 1, pp. 6-28.

\section{Further reading}

Cutler, D.M. and Lleras-Muney, A. (2010), "Understanding differences in health behaviors by education", Journal of Health Economics, Vol. 29 No. 1, pp. 1-28.

Seguin, R.A., Ammerman, A.S. and Connor, L.M. (2018), "Cost-offset community supported agriculture (CO-CSA) plus education improves caregivers' dietary quality and food security in low-income households, as well as caregiver attitudes, self-efficacy, and skills", paper presented at American Public Health Association, 10-14 Nov, San Diego, CA.

US Census Bureau (2016), “2012-2016 American community survey 5-year estimates”,

\section{Author affiliations}

Christine E. Walsh, Department of Health Behavior, University of North Carolina at Chapel Hill, Chapel Hill, North Carolina, USA

Rebecca Seguin-Fowler, Department of Nutrition and Food Science, Texas A\&M University System, College Station, Texas, USA

Alice Ammerman, Department of Nutrition, University of North Carolina at Chapel Hill, Chapel Hill, North Carolina, USA

Karla Hanson, Division of Nutritional Sciences, Cornell University, Ithaca, New York, USA 
Stephanie B. Pitts Jilcott, Department of Public Health, East Carolina University, Greenville, North Carolina, USA

Jane Kolodinsky, Department of Community Development and Applied Economics, College of Agriculture and Life Sciences, University of Vermont, Burlington, Vermont, USA

Marilyn Sitaker, Department of Ecological Agriculture and Food Systems, The Evergreen State College, Olympia, Washington, USA, and

Susan Ennett, Department of Health Behavior, University of North Carolina at Chapel Hill, Chapel Hill, North Carolina, USA

\section{Corresponding author}

Christine E. Walsh can be contacted at: chriseli@live.unc.edu 